\title{
Study of a weather and stain resistant outer concrete wall protecting
}

\section{agent}

\author{
Chunlei Xia ${ }^{1, a}$, Huiqing Xue ${ }^{1, b}$, Weiping Wu ${ }^{1, c}$, Shiyuan $\mathrm{Li}^{1, \mathrm{~d}}$, Yurong $\mathrm{Li}^{1, \mathrm{e}}$,
}

$$
\text { Feng } \mathrm{Yu}^{1, \mathrm{f}}
$$

\author{
${ }^{1}$ Beijing Municipal Engineering Research Institute, Beijing 100037, China \\ a54428052@qq.com, b1602651002@qq.com, c42104729@qq.com, d1129110102@qq.com, \\ e603789649@qq.com, f932809924@qq.com
}

\begin{abstract}
Keywords: fluorocarbon emulsion; acrylic/polyurethane emulsion; concrete wall; protective agent; weather resistance; stain resistance
\end{abstract}

\begin{abstract}
This paper developed a concrete wall protective agent with high weather-ability and contamination resistance. In order to realize the properties of protective agent, acrylic / polyurethane emulsion, fluorocarbon emulsion was used as basic raw material, with ultraviolet absorbent, anti-foam agent, preservative, film forming additive, thickener, etc.. Compared with the existing protective agent, it has excellent anti contamination performance, did not get yellow and discoloration in the ultraviolet irradiation. This agent is a excellent ultra-durable protection layer for concrete exterior wall, which can greatly extend the life of the buildings.
\end{abstract}

\section{Introduction}

To reduce the cost of the concrete structure residential exterior wall, color concrete exterior wall has began to replace the external wall brick and other residential facades. Due to the lack of understanding of the durability of concrete in the past few years, the phenomenon of low durability of concrete in many projects is very prominent. A large number of concrete structures are not as long as the design life will be destroyed, causing great losses to the national economy. The main failure modes of concrete exterior wall are as follows: (1) freezing and thawing damage; (2) the carbonation and steel corrosion damage; (3) alkali aggregate reaction; (4) crack and leakage damage; (5) the comprehensive effect of multiple factors, which has "superimposed effect", will accelerate and aggravate the deterioration of concrete. In recent years, the research of concrete durability has made some progress, but the main use of the "single factor method", such as high frost resistance, rust inhibitor, etc., the practical application effect is not very ideal. How to ensure the structural durability of the design requirements, the main use of the "high performance concrete" technical route, but the actual construction of "high performance concrete easy to crack" the characteristics of structural durability is difficult to guarantee ${ }^{[1,2]}$. Domestic and foreign practices prove that the 
concrete surface protection is a simple and economical method to improve the durability of structure $^{[3,4,5]}$.

At present, the concrete surface protection is mainly based on curing agent, and the protection effect of concrete is only short-term benefit. The weathering of several existing protection agent and anti contamination ability is not ideal, it is easy to getting yellow and dirty, cannot satisfy the aesthetic requirements of concrete wall.

This paper developed a concrete wall protective agent which has high weather ability and contamination resistance. In order to realize the properties of protective agent, acrylic / polyurethane emulsion and fluorocarbon emulsion are used as basic raw material. Ultraviolet absorbent, anti-foam agent, preservative, film forming additive, thickener, etc. are used as additives. Compared with the existing protective agent, this agent has excellent anti contamination performance, not getting yellow and discoloration under long term of ultraviolet irradiation. This agent is applicable to the concrete exterior wall of ultra durable protection layer, extend the life of the building greatly.

\section{Test section}

\section{Test materials}

Acrylic / polyurethane copolymer emulsion: Tianjin extraterrestrial chemical coating Co., Ltd.; Fluorocarbon emulsion: Beijing Heng tong Yun Bo Technology Co., Ltd.; Ultraviolet absorbent: Ever light Chemical Industrial Co., Ltd.; Wetting agent; deforming agent; Preservatives; assistant of film.

\section{Test method}

Adhesion and resistance to acid and alkali with reference to <Film coating for concrete structures protection $>335-2011 \mathrm{JG} / \mathrm{T}$.

Stain resistance with reference to<Synthetic resin emulsion paint for exterior wall> GB/T9755-2001.

Minimum film forming temperature with reference to $<$ Determination of latex paint minimum film forming temperature>9267-1988 GB.

Weathering resistance evaluation with reference to $<$ Paints and varnishes - Rating schemes of degradation of coats $>\mathrm{GB} / 1766-2008$. 


\section{Results and discussion}

\section{Affection of Polyurethane /acrylate copolymer emulsion, fluorocarbon emulsion ratio}

Note: GB/T 9755-2001 on the exterior wall coating requirements: excellent products $\leq 15$; firsts $\leq 15$; qualified $\leq 20$.

Fig. 1 Influence of acrylic polyurethane emulsion and fluorocarbon emulsion ratio on stain resistance

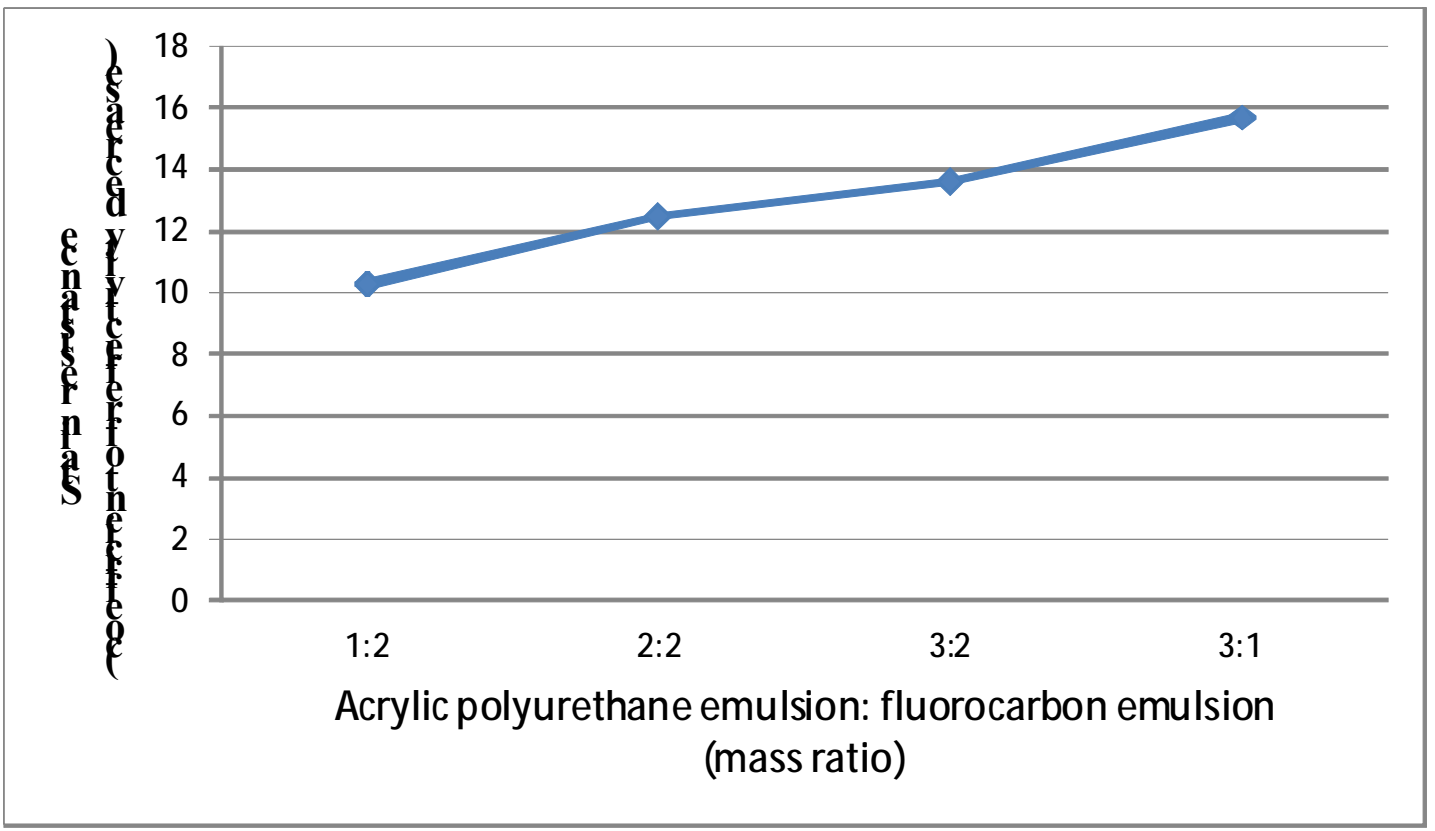

Fluorocarbon emulsion is excellent in stain resistance, durability and adhesion, but the price is high. Polyurethane/acrylate copolymer emulsion is a high elastic emulsion, and the price is lower. This experiment blend polyurethane/acrylate copolymerization emulsion and fluorocarbon emulsion with different proportion, then test the influence of different proportion to tarnish resistance and adhesion.

Stain resistance of agent is indicated by the reflection coefficient decline rate, higher decline rate the worse Stain resistance. As shown in figure 1, stain resistance declined with reduce of the fluorocarbon emulsion ratio. When the mass ratio of $\mathrm{A} / \mathrm{P}$ and fluorocarbon emulsion is $1: 2$, the stain resistance is 10 , which is superior to the requirements of high-class exterior wall coating. When the $\mathrm{A} / \mathrm{C}$ and fluorocarbon emulsion, mass ratio reach to $3: 1$, the stain resistance becomes 15.7 , slightly worse than the requirements of high-class exterior wall coating, but completely conform to the requirements for qualified products.

When synthetic outer wall protective agent, we can choose the appropriate ratio to control the cost and performance according to the requirements of the protective agent. 


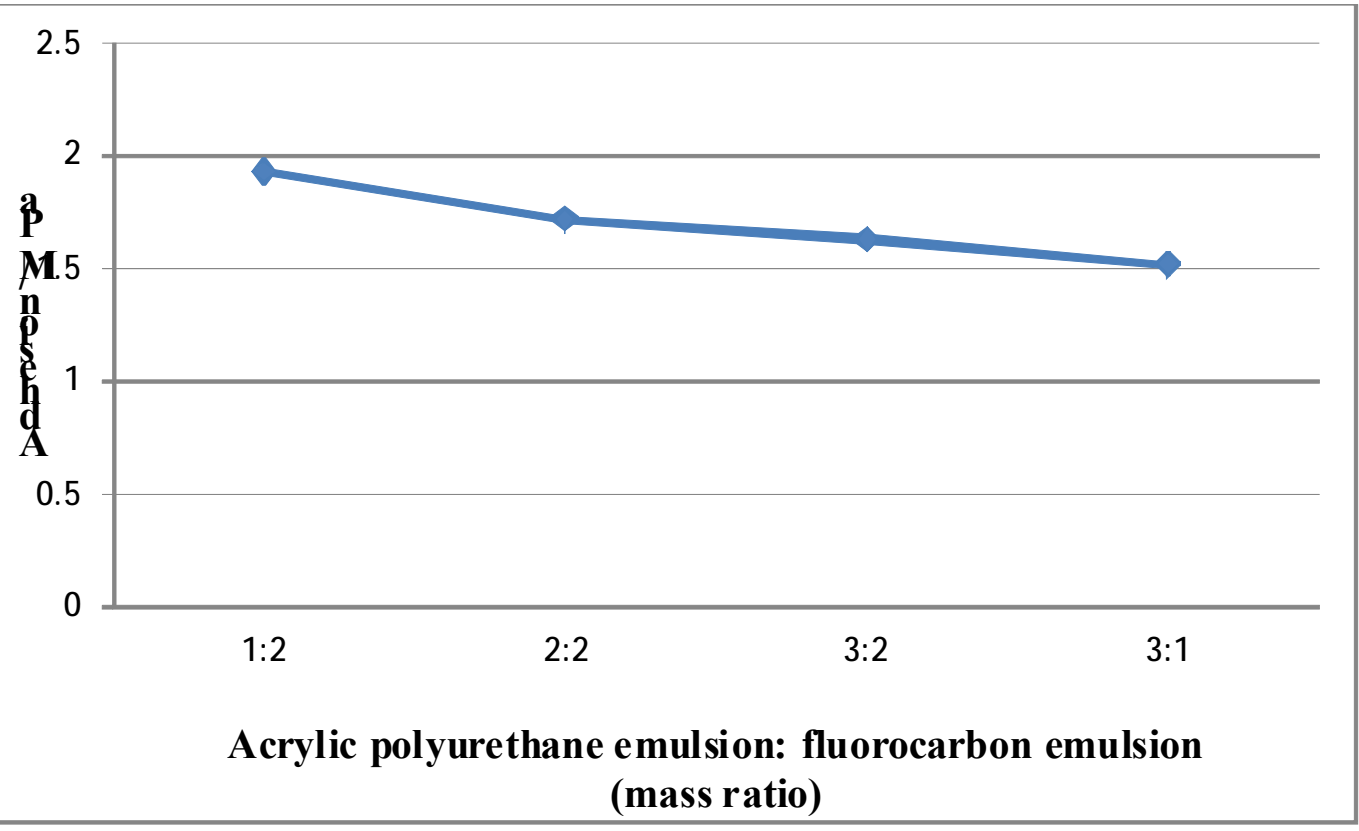

Note: The adhesion requirement of GB/T9755-2001 for exterior wall coating is $\geq 1.5 \mathrm{MPa}$.

Fig.2 Influence of acrylic polyurethane emulsion and fluorocarbon emulsion ratio on adhesion

Fig.2 is the effect of $\mathrm{A} / \mathrm{P}$ and fluorocarbon emulsion ratio on adhesion, with the decline of fluorocarbon emulsion ratio, adhesion decreased from 1.93MPa to $1.52 \mathrm{MPa}$. But the adhesion data still meet the requirement of the standard for adhesion.

\section{Effect of film forming additives on the minimum film forming temperature (MFFT)}

The minimum film forming temperature (MFFT) is theory minimum temperature for the emulsion using. Generally speaking, the MFFT of emulsion should below $10^{\circ} \mathrm{C}$, preferably $5^{\circ} \mathrm{C}$, so as to ensure the construction quality of the emulsion protect agent . High MFFT may bring higher hardness to the film, but film failure appears frequently when construction is in low temperature.

In general, the MFFT of A/P and fluorocarbon emulsion, which is not added film forming additives, is above $25^{\circ} \mathrm{C}$. Therefore, it is necessary to add a suitable film forming additives to reduce the MFFT. Based on experience, this experiment add isothiazolinone derivatives as film forming additives into emulsion to reduce MFFT, the P/C and fluorocarbon emulsion quality ratio is $3: 2$.

Fig. 3 shows the effect of film forming additives to MFFT. Film forming additives added has obvious effect on MFFT reduces, when the adding amount is $2 \%$, MFFT falls from $28^{\circ} \mathrm{Cto} 5$ ${ }^{\circ} \mathrm{C}$.But as a film forming agent adding volume continues to increase, MFFT only reduces slightly. 


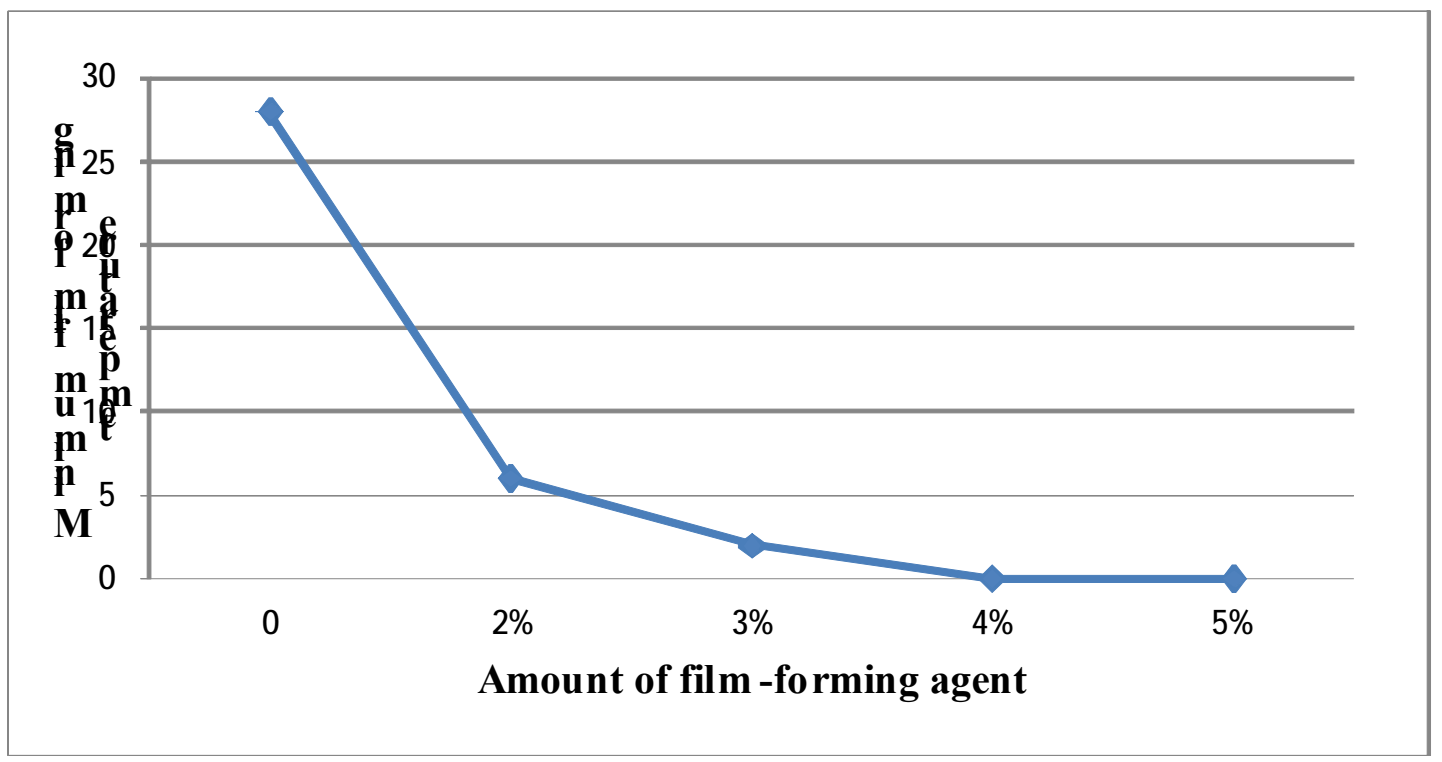

Fig. 3 Effect of amount of film-forming agent on minimum film forming temperature

\section{UV absorber influence on weather resistance}

Due to the long-term exposure of ultraviolet radiation, the external wall protection agent is easy to get yellowing and discoloration, which go against with the appearance of the external wall. Therefore the selection of suitable UV absorber will necessary, this experiment choose sulfonic acid derivative of benzophenone to improve the weather ability of the protective agent, the $\mathrm{P} / \mathrm{C}$ : fluorocarbon emulsion mass ratio is 3:2.

Table 1 Effect of UV absorber on weather resistance (1000h artificial aging test)

\begin{tabular}{ccc|c|c}
\hline $\begin{array}{c}\text { UV } \\
\text { absorber } \\
\text { amount }\end{array}$ & $\begin{array}{c}\text { Color } \\
\text { change } \\
\text { Grade }\end{array}$ & $\begin{array}{c}\text { Degree of } \\
\text { discoloration }\end{array}$ & Powder Grade & Degree of powder \\
\hline 0 & 1 & $\begin{array}{c}\text { Very slight } \\
\text { discoloration }\end{array}$ & 0 & no powder \\
$0.2 \%$ & 0 & $\begin{array}{c}\text { No discoloration } \\
\text { No discoloration }\end{array}$ & 0 & $\begin{array}{l}\text { no powder } \\
\text { no powder } \\
0.3 \%\end{array}$ \\
$0.4 \%$ & 0 & No discoloration & 0 & 0 \\
\hline
\end{tabular}

As seen from table1, when the UV absorber is not added, the color change Grade of the protective agent is 1 , the degree of discoloration is very slight discoloration. When $0.2 \%$ of the UV absorber was added, the color change level changed to 0 , and the degree of discoloration is no change, which reached the highest level of the standard. But with UV absorber content continues to increasing, color change rating is still 0.About the degree of powder, whether the UV absorber is added or not, the protective agent shows no phenomenon of powder. 
Table 2 Effect of UV absorber on weather resistance (2000h artificial aging test)

\begin{tabular}{ccc|c|c}
\hline $\begin{array}{c}\text { UV } \\
\text { absorber } \\
\text { amount }\end{array}$ & $\begin{array}{c}\text { Color } \\
\text { change } \\
\text { Grade }\end{array}$ & $\begin{array}{c}\text { Degree of } \\
\text { discoloration }\end{array}$ & Powder Grade & Degree of powder \\
\hline 0 & 2 & $\begin{array}{c}\text { Very slight } \\
\text { discoloration } \\
0.2 \%\end{array}$ & 1 & $\begin{array}{c}\text { No discoloration } \\
\text { No discoloration }\end{array}$ \\
$0.3 \%$ & 0 & 0 & 0 & no powder \\
$0.4 \%$ & 0 & No discoloration & 0 & $\begin{array}{l}\text { no powder } \\
\text { no powder }\end{array}$ \\
\hline
\end{tabular}

Table 2 is changes of the color and powder of protective agent in $2000 \mathrm{~h}$ artificial aging test. As can be seen from the table 2 , with the increasing of artificial aging time, the degree of discoloration of the protective agent is also increased. When the UV absorber is not added, the color grade of the protective agent is 2. After adding $0.2 \% \mathrm{UV}$ absorber the color grade is 1 , the degree of discoloration is very slight discoloration. With $0.3 \%$ UV absorber the discoloration levels changes to 0 and reach the standards of the highest level. The same with Table 1, whether adding UV absorbent or not, the protective agent shows no phenomenon of powder.

Data shows that $0.3 \%$ of the UV absorber content can significantly improve the color grade of the protect agent in the most stringent experimental conditions, to ensure the protective agent can meet the standard requirements.

\section{Acid and alkali resistance test}

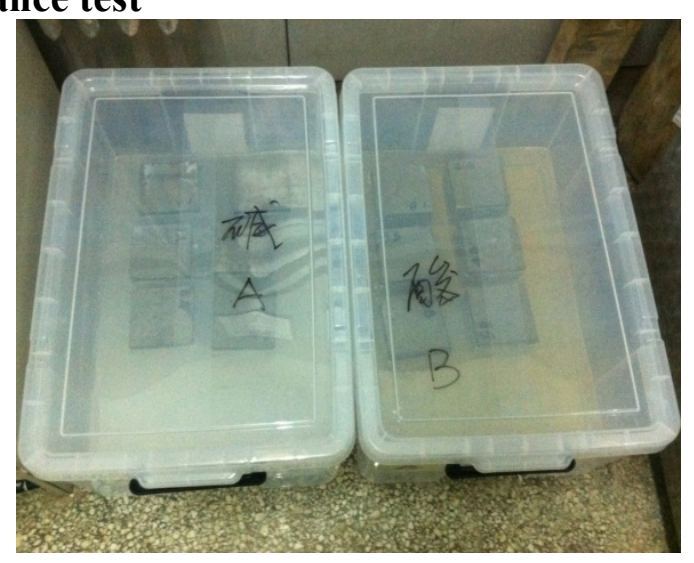

Fig. 4 Acid and alkali resistance test

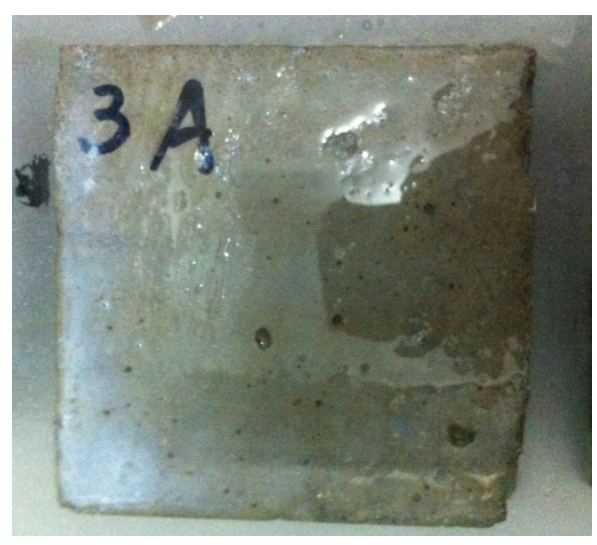

Fig. 5 Alkali resistant test block

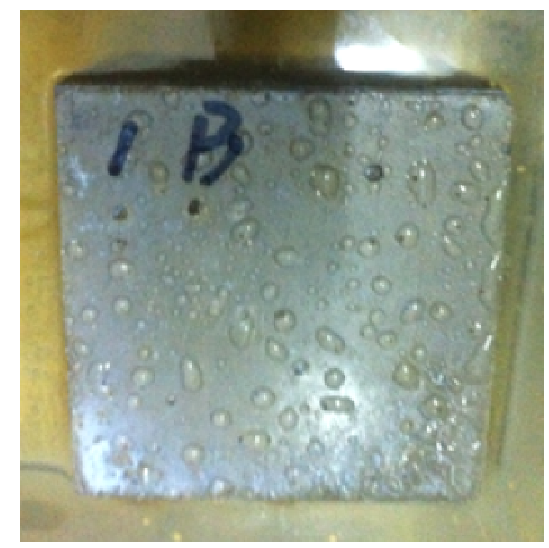

Fig. 6 Acid resistant test block 
Acid and alkali resistance is an important indicators of the protective agent. In accordance with the standard requirements, sample was putted into acid and alkaline solution, see figure 4. 30d after, no bubble, peeling, powder and other phenomena found in the surface(see Figure 5, 6), indicating that the protective agent meet acid and alkali standard.

\section{Other properties of protective agent}

Table3 Other properties of protective agent

\begin{tabular}{c|c|c}
\hline Item & Indicator & Testing standard \\
\hline The state of being in a container & 0 & \\
Constructability & 0 & \\
Construction temperature & $5^{\circ} \mathrm{C}$ & \\
Viscosity $\left(23^{\circ} \mathrm{C}\right)$ & $\geq 80 \mathrm{~s}$ & GB/T 1723-1993 \\
Solid content & $55 \%$ & GB/T 1725-1989 \\
Surface drying time $\left(23^{\circ} \mathrm{C}\right)$ & $\leq 1 \mathrm{~h}$ & GB/T 1728-1989 \\
Actual drying time $\left(23^{\circ} \mathrm{C}\right)$ & $\leq 10 \mathrm{~h}$ & GB/T 1728-1989 \\
\hline
\end{tabular}

\section{Conclusion}

In this paper, acrylic / polyurethane emulsion, fluorocarbon emulsion as basic raw materials, with ultraviolet absorbent, defoaming agent, preservative, film-forming agent, thickening agent and other functional additives to synthesize a weather resistant stain resistant exterior concrete protective agent. Through the laboratory test and field test, the following conclusions are obtained:

(1) The stain resistance declined with reduce of the fluorocarbon emulsion ratio. When the $\mathrm{A} / \mathrm{C}$ and fluorocarbon emulsion, mass ratio reach to $3: 1$, the stain resistance becomes 15.7 , slightly worse than the requirements of high-class exterior wall coating, but completely conform to the requirements for qualified products. When synthetic outer wall protective agent, we can choose the appropriate ratio to control the cost and performance according to the requirements of the protective agent.

(2) Film forming additives added has obvious effect on MFFT reduces, when the adding amount is $2 \%$, MFFT falls from $28^{\circ} \mathrm{C}$ to $5{ }^{\circ} \mathrm{C}$.

(3) As UV absorber sulfonic acid derivative of benzophenone could improve the color change Grade of the protective agent in $2000 \mathrm{~h}$ artificial aging test.

(4) The protective agent of the A/C and fluorocarbon emulsion itself can meet the requirements of acid and alkali resistance, without adding additives to modify.

\section{Reference}

[1] Zhang Zhijun. Study on durability of high performance concrete [J]. Traffic world (Jian Yang Machinery), 2010 (2): 50-52

[2] Gao Fei. Durability analysis of high performance concrete [J]. Shanxi architecture, 2010,36 (18): 
31-33.

[3] Liu Guangyun. Ge Yong. Influencing factors of durability of clean concrete and its improvement measures [J]. Anhui architecture, 2003,10 (4):38-42

[4] Chen Xiaofang, Li Honghui. Experimental study on durability of high performance fair faced concrete [J]. Highway, 2010,4 (4): 168-171

[5] Sun Hongyao, Sun Gaoxia. Discussion on test method for water absorption of organosilicon infiltrated agent on concrete surface. [J]. Highway, 2009 (10): 71-73. 